\title{
Errors in Making Indirect Questions in the Interlanguage of Students at the Faculty of Food Technology
}

\author{
Antonija Šarić \\ Josip Juraj Strossmayer University of Osijek, Faculty of Food Technology Osijek, \\ Kuhačeva 18, 31000 Osijek, Croatia
}

\section{Abstract}

In this paper, the author attempts to identify the most common errors that occur in the interlanguage of students at the Faculty of Food Technology when formulating indirect questions in English language. According to Processability theory (PT), language is acquired in a predictable way, in six stages, the last stage being acquiring word order in subordinate clauses, i.e. cancelling inversion. Since interlanguage presents a dynamic language system that retains some features of the first language or generalizes the second language rules in speech or writing, the origin of errors can be found in mother tongue or in the misapplication of the rules when adopting a second language. Although PT is not concerned with the errors made by the second language learners, this paper will try to identify the origin of errors that appear in the students' interlanguage and the acquisition of the last stage, i.e. the word order in subordinate clauses. In that way, it will be determined whether the errors (inter- or intralingual) made by the students prevent them from acquiring the last stage of PT.

Keywords: developmental stages, interlanguage, Processability Theory, interlingual errors, intralingual errors

\section{Introduction}

The starting point of the second language research is the analysis of the learner's interlanguage which changes during the different stages of development. Research in the field of second language learning and acquisition cover a wide range of problems and approaches to the language learning itself. Different analyses of the learner's interlanguage bring new insights into the interlanguage development and contribute to its understanding. This paper attempts to shed a light on the interlanguage development by analyzing the most common errors when making indirect questions. Furthermore, the development of the interlanguage can be observed by following the six developmental stages proposed by Pienemann (1998) and described within the Processability theory (PT). The last stage in the development of the interlanguage is 
the subordinate clause procedure, i.e. cancelling inversion in indirect questions. Based on the corpus of fifty written exams, this paper will determine the most common errors made by the students of food technology, as well as check whether they have reached the last developmental stage in second language learning.

\section{Error analysis}

The basic assumption which happens in the head of a second language learner is the existence of the so-called interlanguage. This term can be described as a set of rules by which a learner is governed in the linguistic production of a second language. Selinker (1972) defines interlanguage as a cognitive gap that exists between the mother tongue and the language to be learnt. That is why interlanguage contains the rules taken from both languages, i.e. the mother tongue and the second language, but there are also rules that do not correspond to either language. This approach refutes the behaviourist theories, according to which learners solely rely on their mother tongue when learning a second language. However, this does not mean that the mother tongue is completely excluded from learning a second language, which is also observable from the errors made by the second language learners, since they can be divided into inter- and intralingual. Error analysis was the first serious attempt in the analysis of the learner's interlanguage with the aim of determining how the learners acquire their second language. It peaked in the 1960s and 1970s. Counting and classifying errors can be contributed to the work of Corder (1967) who even developed an error analysis methodology. At the very beginning, error analysis was concerned with the question whether the errors made by the second language learners were the result of the first language (L1) transfer or the creative constructions that reveal the specific rules created by the learners which are very similar to those made by the children when acquiring their mother tongue. The presence of errors reflecting the first language structures was considered the evidence of transfer, i.e. an interlingual error, whereas the presence of errors similar to those that occur when acquiring the first language was considered an intralingual error.

According to Scovel (2015) intralingual errors can be explained as:

"...the confusion a language learner experiences when confronting patterns within the structure of a newly acquired language, irrespective of how the target language patterns might contrast with the learner's mother tongue" (Scovel, 2001: p. 51)

There are different ways of classifying errors. According to causes or sources of errors Richards (1970) distinguishes three types of errors:

Interference errors which occur as a result of the use of the elements of one language when speaking another and they can be observed in morphology, syntax, vocabulary and pronunciation. An example of such an error might be when a German learner of English as a second language says I go not because it corresponds to a German sentence Ich gehe nicht. 
Intralingual errors which reflect the general characteristics of rule learning such as faulty generalization, incomplete application of the rule or a failure when applying the corresponding rule. Intralingual errors can be further divided into overgeneralization errors that are made when a learner creates a deviant structure based on other structures in the target language (he can sings instead of He can sing or he sings), then ignorance of rule restrictions (when learners apply the rules to wrong contexts, e.g. He made me to rest) incomplete rule application, opposite to overgeneralization, according to James (1998) (a failure to fully develop a structure, e. g. You like to sing? instead of interrogative word order Do you like to sing?) and false concepts hypothesized (when the learner does not fully understand a distinction in the target language, e.g. One day it was happened). According to Kaweera (2013) exploiting redundancy can also be counted as an intralingual error which happens when learners repeat words or phrases unnecessary (e.g. I repeated it again)

Developmental errors which arise when the learner attempts to create hypotheses about the target language on the basis of limited experience.

However, the most authors distinguish among transfer errors (or interference errors according to Richards) and intralingual errors. Since it is not simple to differentiate between transfer and intralingual errors, Dulay and Burt (1974) classified the errors into: developmental, interference and unique errors. Developmental errors are similar to those that happen when acquiring the first language (e.g. he not eat). Interference errors reflect the first language structure, e.g. the man skinny and unique errors which do not belong to either category.

According to Bhela (1999 in Kaweera, 2013), the source of the interference errors can be found in the word for word translation strategy or thinking in the mother tongue language. Furthermore, interference errors (Kaweera, 2013) can be divided into L1 lexical interference (e.g. I play a computer), syntactic interference (e.g. have many trees in the university) and discourse interference (not using paragraph structure in writing).

Corder (1967) emphasizes the importance of errors for three reasons: first of all, errors show how much the learner has learnt so far and what remains to be learnt. Secondly, errors show insight into the way the language is learnt or acquired and finally they reveal the strategies the learners use when discovering the language. However, error analysis was criticized for many reasons. Firstly, it failed to show how learners progress in language learning over time. Secondly, it provided a static insight in second language acquisition. Finally, it only gained insight into what learners do and it failed to show what strategies learners use whey they find a certain phrase or a structure too difficult. On the other hand, error analysis contributed to the second language acquisition to a great extent. It helped the behaviourist and mentalist debates to collect empirical evidence pointing out to the fact that sources of learner's errors cannot only be ascribed to interference and showing that error making is a standard 
procedure in language learning. Although error analysis was popular in the 1970s, it is still applied when describing the learner's interlanguage.

European Framework of Reference for Languages (CEFL) still describes requirements for grammatical accuracy with a constant emphasis on the number and a type of errors neglecting thus the development of grammar (Pallotti, 2010).

\section{Processability theory (PT)}

Since it was eventually discovered that the use of error analysis does not provide the full image of language acquisition, considering that the learners' language is observed as a collection of errors, and studying those errors does not explain the method by which learners acquire language skills over time. This was the reason why researchers recognised the need to study the learners' language as a whole, in order to explain the interlanguage that the learners create in various stages of development. The Processability Theory (PT), which is based on the cognitive approach to the acquisition of a second language, attempts to explain the way in which learners who are learning a second language are reforming their understanding of interlanguage structures, so those would conform to the structures of the other language. According to PT, the learners who are learning a second language are able to reform, i.e., process the structures of the other language using the method and according to the order which is appropriate for their current stage of development. Therefore, the Processability Theory is concerned with research into the stages of development, by emphasizing the fact that language develops in a regular and predictable way, and it is possible to determine the developmental path for the acquisition of any language. Processability Theory is ascribed to Manfred Pienemann (1998) and it was created as a response to the deficiencies of the theories that preceded it (multidimensional model, strategies approach, the teachability hypothesis, and the predictive framework), which were also concerned with the sequence of acquisition of a second language. The basics of the Processability Theory are presented in the multidimensional model which was created as part of the ZISA project (German Zweitspracherwerb Italienischer und Spanisher Arbeiter). The ZISA research was based on the acquisition of the word order in the German language for 45 adult native speakers of Italian, Spanish, and Portuguese languages, and it explains the stages of acquisition of German as a second language. The stages indicate implicational scaling, i.e., the acquisition of rules at a certain stage necessitates the acquisition of the rules from the previous stages (Meisel, Clahsen, and Pienemann, 1981). Up until now, PT has been applied not only to the German language, but to many other languages as well. In most cases it was English (e.g., Fetter 1996; Mansoury and Duffy, 2005; Ellis, 2008; Sakai, 2008), then Swedish (Philipsson, 2007; Hakansson and Norrby, 2010), Japanese (Kawaguchi, 2005), French (Bartning, 2000; Devaele and Veronique, 2001), and many other languages, including Serbian (Medojević, 2009). The topic of this paper is the developmental path for the acquisition of the English language, with the focus on the final developmental stage, i.e. acquiring word order of a subordinate 
clause with the aim of determining if the mentioned developmental stage was acquired (English morphology and syntax develops in six stages presented in Table 1). For the purpose of corpus analysis, in his research Pienemann uses emergence analysis, which is defined as the first systematic use of a structure and the beginning of the process of acquisition of a certain structure (Pienemann, 1998). In order to determine if a certain structure has emerged in the interlanguage, it is necessary to separate systematic productivity from formulae. Productivity is measured by the number of tokens and the systematic use of lexical/morphological variations of those tokens. According to Pienemann (1998), one productive token in four contexts is evidence of emergence, while Mansouri (2005 in Dyson, 2010) requires at least two lexical and morphological contrasts, and Zhang (2004 in Dyson, 2010) uses the minimum of four tokens with lexical variations in at least two. While analysing the acquisition of syntax, i.e., the word order in the Japanese language, Kawaguchi (2005) analysed the position of the lexical verb in a sentence, and required one token as the evidence of emergence. This paper also required one token, but considering that emergence is defined as the beginning in the process of the acquisition of a certain structure, the accuracy requirement is set at $80 \%$. Considering the fact that even the native speakers cannot use fully accurate structures, the accuracy requirement is usually set at 80-90\% (Ellis, 1994). Vainikka and Young-Sholten (in Pallotti, 2007) consider a particular structure acquired if it is accurately applied in $60 \%$ of cases, Ellis (1998 in Pallotti, 2007) requires a 75\% accuracy, Andersen (1978 in Pallotti, 2007) $80 \%$ and Dulay and Burt (1974) require an accuracy of $90 \%$ in order to consider a particular structure acquired.

As stated above, a large amount of research confirms the postulates of the Processability Theory. However, several deficiencies have also been detected for the mentioned theory. For example, Pienemann (1998) emphasizes the importance of emergence of a certain structure, but fails to explain what happens after the emergence, i.e., when is it possible to determine that a certain structure has actually been acquired (Mellow, 1996). This hypothesis is also partially supported by Hulstijn (2015), who believes that future interlanguage research should focus on more than just the first indicators for the acquisition of a certain structure (emergence), it should also focus on the entire developmental path of a certain structure, i.e., it should provide the overview of a certain structure, from its first emergence until it is fully acquired.

Considering the objections directed at the emergence criterion, and taking into account that it represents only the beginning of the acquisition process, in this paper we used the criterion according to which the final developmental stage was acquired if it was used in 80 or more percent of the cases.

Considering that Pienemann (1998) applied the Processability Theory exclusively on speech production, Jordan (2004) believes that the area of application of the Processability Theory is limited, because it does not take into account other tasks like 
grammatical evaluation tests and grammatical tasks, which is also mentioned by Pallotti (2007), who considers that these should also be included in the analysis by the use of the emergence criterion, because the aim is to collect a large corpus, in order to create a detailed analysis of the learners' interlanguage. For that reason, the Processability Theory was also applied to the written mode. However, in order to present the full image of the learners' language, future research could include both spoken and written production.

Table 1. Developmental stages for English morphology and syntax (Pienemann, 2005b, p. 24)

\begin{tabular}{|c|c|c|c|c|}
\hline Stage & $\begin{array}{l}\text { Processing } \\
\text { Procedure }\end{array}$ & L2 process & Morphology & Syntax \\
\hline 6 & $\begin{array}{l}\text { Subordinate } \\
\text { clause } \\
\text { procedure }\end{array}$ & $\begin{array}{l}\text { Main and } \\
\text { subordinate } \\
\text { clause }\end{array}$ & & $\begin{array}{l}\text { Cancel } \\
\text { inversion }\end{array}$ \\
\hline 5 & $\begin{array}{l}\text { Sentence } \\
\text { procedure }\end{array}$ & $\begin{array}{l}\text { Inter-phrasal } \\
\text { agreement }\end{array}$ & $\begin{array}{l}\text { Subject-verb } \\
\text { agreement } \\
\text { (3rd person } \\
\text { singular -s) }\end{array}$ & $\begin{array}{l}\text { Do2nd, } \\
\text { Aux2nd }\end{array}$ \\
\hline 4 & $\begin{array}{l}\text { Verb phrase } \\
\text { procedure }\end{array}$ & $\begin{array}{l}\text { Inter-phrasal } \\
\text { agreement }\end{array}$ & Tense agreement & $\begin{array}{l}\mathrm{Y} / \mathrm{N} \\
\text { inversion } \\
\text { Copula } \\
\text { inversion }\end{array}$ \\
\hline 3 & $\begin{array}{l}\text { Noun phrase } \\
\text { procedure }\end{array}$ & $\begin{array}{l}\text { Phrasal } \\
\text { information }\end{array}$ & $\begin{array}{l}\text { Noun phrase } \\
\text { agreement } \\
\text { (Negation+Verb) }\end{array}$ & $\begin{array}{l}\text { Adverb } \\
\text { fronting/ } \\
\text { Do- fronting }\end{array}$ \\
\hline 2 & $\begin{array}{l}\text { Category } \\
\text { procedure }\end{array}$ & $\begin{array}{l}\text { Lexical } \\
\text { morphology } \\
\text { Possessive } \\
\text { pronouns }\end{array}$ & Plural & $\begin{array}{l}\text { Canonical } \\
\text { word order }\end{array}$ \\
\hline
\end{tabular}


Noun

Invariant forms

Single

procedure

constituents

\section{Methodology}

For corpus analysis, two written activities were administered to fifty $2^{\text {nd }}$ year students of the faculty of food technology. In the first activity, the students were asked to translate ten sentences from Croatian into the English language. The sentences had to be translated using the indirect question word order. In the second activity, which consisted of five sentences, the students were asked to correct five incorrect sentences. Again, they had to pay attention to word order in indirect questions. This type of exercise was administered to students to check whether they use the word order in indirect questions correctly, i.e. if they use the word order of a normal positive sentence, which means cancelling the inversion. Taking into account that the students have learnt English for 14 years, the aim of this research was to check whether the last developmental stage, according to PT, was acquired. As previously explained, the accuracy requirement is set at $80 \%$, i.e. last developmental stage will be considered acquired if the students used indirect word order correctly in $80 \%$ of cases. Furthermore, the source of errors will be determined, so as to check whether the most errors appear because of the interference with the mother tongue or if they are intralingual which happen because of overgeneralization, ignorance of rule restrictions, incomplete rule application or wrong concepts hypothesized.

\section{Results}

The results of this research were attained from the corpus which consisted of 10 sentences in the first activity. They had to be translated from Croatian into English. Next activity was aimed at checking whether they students are able to correct grammatically incorrect sentences. Since the activities were administered to fifty students, the accuracy percentage was calculated for each sentence in the activity 1 (Table 2) and the activity 2 (Table 3 ). As can be seen from Table 2, the students were the least successful in translating the fifth sentence since they used the wrong word order. They were quite successful when translating the first two and the last sentence. The possible explanation is that they often hear these sentences, especially the first one, so they memorize it as chunks. However, the accuracy criterion was not met, so it can be claimed that they did not acquire the last developmental stage.

As far as the second activity is concerned (Table 3), we can see that they were even less successful. They struggled with correcting the fourth sentence. They did not notice that the word order was wrong, so we can reach the same conclusion: they failed to correct the indirect questions and the last developmental stage was not acquired. Altogether, they made errors in $65 \%$ of cases, the accuracy percentage being only $35 \%$ (Table 4 ). 
Table 2. Accuracy percentage of translated indirect questions

\begin{tabular}{|c|c|c|}
\hline \multicolumn{3}{|l|}{ Activity 1} \\
\hline $\begin{array}{l}\text { sentence } \\
\text { no. }\end{array}$ & correct sentence in English & $\%$ accuracy \\
\hline 1 & Sorry, could you tell me where the bus station is? & $40 \%$ \\
\hline 2 & I would like to know when this restaurant is closing. & $44 \%$ \\
\hline 3 & I would like to know how much this ring costs. & $36 \%$ \\
\hline 4 & Could you tell me if your friend lives in London? & $32 \%$ \\
\hline 5 & Could you tell me why he was late for the meeting? & $18 \%$ \\
\hline 6 & I wonder why she is unhappy. & $34 \%$ \\
\hline 7 & $\begin{array}{l}\text { Could you tell me if she had breakfast before she went to } \\
\text { school? }\end{array}$ & $36 \%$ \\
\hline 8 & Could you tell me when this lecture is going to end? & $26 \%$ \\
\hline 9 & Could you tell me if he wrote his homework? & $28 \%$ \\
\hline 10 & I wonder why he hasn't passed any of his exams. & $54 \%$ \\
\hline
\end{tabular}

Table 3. Accuracy percentage of error correction

\begin{tabular}{|l|l|l|}
\hline \multicolumn{2}{|l|}{ Activity 2} \\
\hline $\begin{array}{l}\text { Sentence } \\
\text { no. }\end{array}$ & Incorrect indirect question & $\%$ accuracy \\
\hline 1 & Can you tell me why is he unhappy? & $34 \%$ \\
\hline 2 & Can you tell me where has Lucy been? & $18 \%$ \\
\hline
\end{tabular}




\begin{tabular}{|l|l|l|}
\hline 3 & Do you know where is the post office? & $64 \%$ \\
\hline 4 & I'd like to know how long have you lived here? & $10 \%$ \\
\hline 5 & I'd like to know how much do you earn? & $16 \%$ \\
\hline
\end{tabular}

Table 4. Percentage of correct and incorrect sentences in the Activity 1

\begin{tabular}{|l|l|}
\hline \multicolumn{2}{|l|}{ Activity 1} \\
\hline Correct sentences (\%) & Incorrect sentences (\%) \\
\hline $174(500)$ & $326(500)$ \\
$35 \%$ & $65 \%$ \\
\hline
\end{tabular}

Next, the focus was on the types of errors made by the students. As we can see (Tables 5 and 6), the studently mostly used wrong word order. This is a typical interlingual error, since they directly translate the sentences from their mother tongue, thus cancelling the inversion. Other types of errors were classified as intralingual ones, since the students hypothesized false concepts (e.g. I wonder why he wasn't pass any of his exams), applied incomplete rules (e.g. I wonder how much does this ring cost) or overgeneralized the rules (e.g. Could you tell me had she had breakfast before she went to school). The other errors that they made were due to the sentences they did not translate or verbs they omitted. Finally, the errors were divided into two main categories, intra- and interlingual ( 23 which were not translated were excluded from the analysis). As Table 6 shows, interlingual errors prevail, because the students are influenced by their mother tongue and translate the sentences directly, thus, ignoring the indirect question word order.

Table 5. Type of error

Type of error - Activity 1

\begin{tabular}{|c|c|c|c|c|c|c|}
\hline $\begin{array}{l}\text { wrong } \\
\text { word } \\
\text { order } \\
\text { (\%) }\end{array}$ & $\begin{array}{l}\text { false } \\
\text { concepts } \\
\text { hypothesized } \\
\text { (\%) }\end{array}$ & $\begin{array}{l}\text { incomplete } \\
\text { rule } \\
\text { application } \\
\text { (\%) }\end{array}$ & $\begin{array}{l}\text { overgeneralization } \\
\text { (\%) }\end{array}$ & $\begin{array}{l}\text { subject- } \\
\text { verb } \\
\text { agreement } \\
(\%)\end{array}$ & $\begin{array}{l}\text { verb - } \\
\text { missing } \\
(\%)\end{array}$ & $\begin{array}{l}\text { sentence } \\
\text { not } \\
\text { finished } \\
\text { (\%) }\end{array}$ \\
\hline
\end{tabular}




\begin{tabular}{|l|l|l|l|l|l|l|}
\hline $\begin{array}{l}149 \\
(500)\end{array}$ & $43(500)$ & $70(500)$ & $27(500)$ & $12(500)$ & $2(500)$ & $23(500)$ \\
$30 \%$ & $9 \%$ & $14 \%$ & $2 \%$ & $2 \%$ & $0,4 \%$ & $5 \%$ \\
\hline
\end{tabular}

Table 6. Source of error

\begin{tabular}{|l|l|}
\hline \multicolumn{2}{|l|}{ Source of error } \\
\hline Interlingual (\%) & Intralingual (\%) \\
\hline $158(303)$ & $145(303)$ \\
$52 \%$ & $48 \%$ \\
\hline
\end{tabular}

\section{Conclusion}

The aim of this paper was to check if the students managed to acquire the last developmental stage according to the Processability Theory, to detect the most common errors and determine their sources. After corpus analysis, the following conclusions were drawn: students did not acquire the last developmental stage, since they managed to translate correctly only $35 \%$ of all sentences. Furthermore, they are far away from acquiring this stage (the required accuracy percentage was set at $80 \%$ ). As for future studies, it would be interesting to check whether the students acquired the previous developmental stage, where they are supposed to put the auxiliaries to the second position. The starting point for this research was the fact that the students have been learning English for 14 years, so that is why the focus was on the last developmental stage. But being aware that they are not even close to the acquisition of the last stage on their developmental path of the English syntax, the teachers could adjust their teaching to the students' current developmental stage. That way they would not require from students more than they are able to process and learn. Since PT was criticized because it focused only on the speech production, this paper was applied to the written mode. The results would be more consistent if the PT was applied to oral production, so it would be interesting and useful to do it in future. Furthermore, most errors the students made were due to the incorrect word order, because the students use the same word order as in their mother tongue, i.e. they do not cancel the inversion in indirect questions. The source of the errors comes from the interference with their mother tongue, so these errors are classified as 
interlingual. In order to prevent these types of errors, the students could be taught to memorize words as chunks, which might prevent them from the interference with their mother tongue and then another research could be conducted to check whether the students still make the same errors or they made progress. Understanding the types of errors the students make could be very useful to the teachers because once the errors are detected, the teachers can gain insight into the difficulties the students are confronted with while learning and can help them to progress in learning. Furthermore, it could contribute to accurate and precise teaching and thus be a great help to teachers. 


\section{References}

[1] Bartning, I. (2000). Gender agreement in L2 French: Pre-advanced vs advanced learners. Studia Linguistica, 54(2), 225-237.

[2] Corder, S.P. (1967). The significance of learners' errors. IRAL, 10 (4), 159170.

[3] Devaele, J.-M., Veronique, D. (2001). Gender assignment and gender agreement in advanced French interlanguage: a cross-sectional study. Bilingualism: Language and Cognition, 4(3), 275-297.

[4] Dyson, B. (2010). Learner language analytic methods and pedagogical implications. Australian Review of Applied Linguistics, 33(3), 30.1-30.21.

[5] Ellis, R. (2008). Investigating grammatical difficulty in second language learning: Implications for second language acquisition research and language testing. International Journal of Applied Linguistics, 18(1), 4-22.

[6] Fetter, R. (1996). A test of Pienemann and Johnston's tentative developmental stages in ESL Development. CILT Reports and Papers, 6, 1-16.

[7] Hakansson, G., Norrby, C. (2010). Environmental influence on language acquisition: Comparing second and foreign language acquisition of Swedish. Language Learning, 60(3), 628-650.

[8] Hulstijn, J. H. (2015). Discussion: How different can perspectives on L2 development be? Language Learning, 65(1), 210-232.

[9] James, C. (1998). Errors in Language Learning and Use. Exploring Error Analysis. Longman, Essex.

[10] Jordan, G. (2004). Theory construction in second language acquisition. Amsterdam: John Benjamins.

[11] Kawaguchi, S. (2005). Argument structure and syntactic development in Japanese as a second language. In M. Pienemann (Eds.), Cross-linguistic aspects of processability theory (pp. 253-299). Amsterdam/Philadelphia: John Benjamins Publishing Company.

[12] Kaweera, C. (2013). Writing Error: A review of Interlingual and Intralingual Interference in EFL Context. English Language Teaching, 6(7), 9-18.

[13] Mansouri, F., Duffy, L. (2005). The pedagogic effectiveness of developmental readiness in ESL grammar instruction. Australian Review of Applied Linguistics, 28(1), 81-99.

[14] Medojević, L. (2009). Applying Processability Theory and Its Extension to Serbian as a Family and Community Language in Australia. In J-U. Keßler \& D. Keatinge (Eds.), Research in Second Language Acquisition: Empirical Evidence across Languages (pp. 267-293). Newcastle upon Tyne: Cambridge Scholars Publishing.

[15] Meisel, J. M., Clahsen, H. i Pienemann, M. (1981). On determining developmental stages in natural second language acquisition. Studies in Second Language Acquisition, 3(2), 109-135. 
[16] Mellow, D. J. (1996). On the primacy of theory in applied studies: A critique of Pienemann and Johnston. Second Language Research, 12(3), 304-318.

[17] Pallotti, G. (2010). Doing interlanguage analysis in school context. In I. Bartning, M. Martin \& I. Vedder (Eds.), Communicative proficiency and linguistic development: intersections between SLA and language testing research (pp.159-191). European second language association 2010.

[18] Philipsson, A. (2007). Interrogative Clauses and Verb Morphology in L2 Swedish: Theoretical Interpretations of Grammatical Development and Effects of Different Elicitation Tehniques (Doctoral thesis, Stockholm University, Sweden). Retrieved from http://www.divaportal.org/smash/get/diva2:197193/FULLTEXT01.pdf.

[19] Pienemann, M. (1998). Language processing and second language development: Processability theory. Studies in Bilingualism. Amsterdam: John Benjamins Publishing Company.

[20] Pienemann, M. (2005b). An introduction to Processability Theory. In M. Pienemann (Eds.), Cross-linguistic aspects of processability theory (pp.6185). Amsterdam/Philadelphia: John Benjamins Publishing Company.

[21] Pienemann, M. (Eds.) (2005). Cross-linguistic aspects of processability theory. Amsterdam/Philadelphia: John Benjamins Publishing Company.

[22] Richards, J. C. (1970). A non-contrastive approach to error analysis. English language teaching journal, 25(3), 204-219.

[23] Sakai, H. (2008). An analysis of Japanese university students' oral performance in English using processability theory. Elsevier System, 36, 534549.

[24] Selinker, L. (1972). Interlanguage. IRAL, 10 (3), 209-231. 